\title{
A DOMESTICAÇÃO DOS AGENTES EDUCATIVOS: HÁ ALGUMA LUZ NO FIM DO TÚNEL*
}

\author{
Corinta Maria Grisolia Geraldi, \\ da Universidade Estadual de Campinas \\ JoÃo WanderLEy GeraldI, \\ da Universidade Estadual de Campinas
}

\begin{abstract}
Resumo: Neste estudo retoma-se a questão da relação triádica constitutiva do ofício: alunos, professor e conhecimento, verificando como ao longo da história esta relação definiu diferentes "identidades" para o professor. Sobretudo nas últimas décadas, as políticas públicas de currículo nacional, avaliações nacionais e programa de aquisição de livros didáticos, ou mesmo de pacotes pedagógicos, produziram uma domesticação dos agentes educativos que passaram a nortear seu ensino pelas exigências postas pelo sistema como um todo, com perda quase total de autonomia. A luz no fim do túnel vem precisamente dos espaços políticos que iluminaram esta mesma domesticação: o modelo norte-americano que, tendo fracassado, volta-se para a construção de uma maior autonomia nos processos didáticos e pedagógicos. A exemplificação deste processo se faz com base no ensino da linguagem.
\end{abstract}

Palavras-chave: Formação do professor. Identidade profissional. Ensino de linguagem. Avaliação.

Como professor devo saber que sem a curiosidade que me move, que me inquieta, que me insere na busca, não aprendo nem ensino. Exercer a minha curiosidade de forma correta é um direito que tenho como gente e a que corresponde o dever de lutar por ele, o direito à curiosidade. Com a curiosidade domesticada posso alcançar a memorização mecânica do perfil deste ou daquele objeto, mas não o aprendizado real ou o conhecimento cabal do objeto.

(Paulo Freire, Pedagogia da autonomia)

\footnotetext{
* Artigo recebido em 20/9/2011 e aprovado em 15/11/2011.
} 
INTRODUÇÃO

Se há algo em educação com que todos concordam é que o ensino público vai mal: se o ingresso à escola básica está quase universalizado, a permanência, as aprendizagens dos diferentes saberes, conhecimentos e culturas não têm se viabilizado. Dois processos de exclusão social estão aí presentes: a reprovação (que tira a responsabilidade dos sistemas educativos pelos seus resultados) ou a aprovação automática (que cria falsamente a ilusão do acesso aos bens culturais, de forma irreversível, pois a certificação não corresponde à aprendizagem).

A obviedade é parte do senso comum e tem sido manchete dos principais jornais escritos e televisionados do país: a educação no Brasil não vai bem; o ensino público tem muitos problemas. Nada é novo: nova é a preocupação das elites com a situação da educação, a partir da década de 1990. Por que será? Cabe-nos ir além do jornal, da propaganda, procurando qualificar essas mensagens e dados estatísticos para compreender alguns pontos da tecedura dessa trama, detectar onde estão seus nós, localizar possíveis lugares de puxar o fio, descobrir caminhos de um novo bordado, examinando o escandaloso avesso do tecido.

Nosso objetivo aqui é puxar um fio, ao menos, para tentar enxergar o avesso do bordado. Nosso fio serão algumas considerações sobre o programa neoliberal implementado no país desde o governo Collor, com sua nova abertura dos portos, que atingiu todas as esferas de nossas atividades. Uma mudança significativa nas políticas econômicas não se faz sem que de roldão todas as outras políticas Ihes sigam.

Assim, pretendemos nos ocupar com questões atinentes à política neoliberal na área da educação, sem qualquer pretensão de originalidade. Retornar ao tema nos parece fundamental para que não esqueçamos que as práticas efetivas de sala de aula, e particularmente as práticas de formação continuada dos professores, estão extremamente vinculadas a estas políticas.

Recordemos os primeiros passos realizados no governo Fernando Henrique Cardoso, sob o comando do ministro Paulo Renato Souza: a) elaboração dos Parâmetros Curriculares Nacionais; b) implantação dos sistemas de avaliação em todos os níveis de ensino - hoje sob as siglas SAEB, ENEM, ENADE; c) política de arrocho [e quase estrangulamento] das universidades públicas federais; e d) abertura para exploração do capital privado do nicho de mercado da educação, com uma política de expansão do ensino superior privado "nunca antes vista neste país", a causar inveja até aos áureos tempos da ditadura militar. ${ }^{1}$ 


\section{DomesticaÇÃo dos AgENTES}

Nos anos finais da ditadura, com as eleições dos primeiros governos de oposição (1982), depois reforçados pela redemocratização (1985), praticamente todas as secretarias estaduais de educação - e mesmo secretarias municipais de educação, tendo São Paulo como ponto de partida - escreveram suas propostas curriculares para os diferentes componentes do currículo de ensino fundamental (do então Ensino de 1. ${ }^{\circ} \mathrm{Grau}$ ).

Essas propostas foram elaboradas com maior ou menor participação dos professores, mas sempre com sua presença, ora na forma de representantes, ora na forma de seminários abertos para discussão, ora na forma de coleta de sugestões nas diferentes escolas das respectivas redes. Vivíamos sob o signo político da "participação", após um jejum de vinte anos! Isto não quer dizer que não houvesse a defesa de programas mais amplos e de nível nacional. Um exemplo desta tendência foi a designação, pelo Presidente da República já em 1985, de uma comissão para elaborar diretrizes para o ensino de língua portuguesa. Mas mesmo nesta área, continuou, até a elaboração dos PCNs, uma liberdade maior de definição dos objetivos, dos conteúdos, das metodologias de ensino.

Iniciado o governo FHC, a grande política educacional, levantando a bandeira da eficiência e eficácia dos sistemas de ensino, foram os vários programas de avaliação. A primeira delas se deu no ensino superior, com o então chamado popularmente de Provão, que a cada ano ia incluindo um maior número de cursos de graduação. As reações foram distintas entre os estudantes. Muitos boicotaram a realização da prova, pelo não comparecimento, e quando obrigatório, pelo comparecimento para apenas assinarem presença. Em consequência, alguns cursos obtiveram notas baixas e obviamente toda hierarquização desejada pelo sistema se tornou equivocada: grandes universidades, com cursos reconhecidos e notas baixas. ${ }^{2}$ Não é só a água mole que de tanto bater, fura. Também água forte: as pressões de todos os lados, incluindo obrigatoriedade em algumas universidades ou a redução do número de bolsas de iniciação científica para os graduandos, foram amolecendo as reações e domesticando os estudantes. Até que fazer o Enade se tornou condição para a formatura. ${ }^{3}$

A domesticação dos níveis médio e fundamental foi mais rápida, mais precisa e certamente de efeitos mais devastadores. No que concerne aos estudantes do ensino fundamental, as provas se tornaram uma atividade entre outras a que se submetem na escola. Mais recentemente, até crianças de 8 anos são submetidas a provas nacionais: a Prova Brasil. O exame de 
ensino médio, produtor das mais badaladas hierarquizações de escolas, vai-se fazendo cada vez mais obrigatório na medida em que a obtenção de bolsas de estudos - PRÓ-UNI, por exemplo - depende das notas aí obtidas. Somase a isto a adesão das universidades que paulatinamente vão-se eximindo de realizar seus próprios concursos de ingresso, assumindo as classificações dadas pelo Enem. Mais uma vez, em nome da eficiência e economia de meios, abre-se mão do processo decisório, das qualificações próprias e específicas, para um exame nacional baseado quase que exclusivamente na retenção de conhecimentos.

Infelizmente este sistema de avaliação e hierarquização sofreu nos últimos anos um aprofundamento ainda maior, sob a batuta de Fernando Haddad: além da "provinha Brasil" para diagnóstico com algumas escolas, a prova Brasil para as crianças de oito anos de idade, o atual ministério fez campanha nacional do Índice de Desenvolvimento da Educação Básica IDEB - em que se sugere aos pais que saibam qual o índice da escola de seus filhos (como se eles pudessem simplesmente trocar de escola e lhes fossem fornecidos todos os meios para transporte e material para seus filhos estudarem nas escolas que não sejam da periferia onde moram)! E não faltou deputado para propor projeto de lei obrigando as escolas a exporem seu índice nas portas de entrada...

Mas para realizar provas nacionais era preciso estabelecer programas nacionais. E eles vieram na forma dos PCNs, e não dá para deixar de salientar: são parâmetros. Eles não foram elaborados como propostas ou programas, mas como parâmetros com base nos quais as provas seriam elaboradas. Não sendo programas, não são obrigatórios. Mas sendo parâmetros, tornam-se mais impositivos do que os velhos programas nacionais. Uma imposição nada sutil, porque como ideologicamente se defende que os exames servem como diagnóstico para definir ações de melhoria do ensino, de fato as hierarquizações mostradas na imprensa servem ao capital: informam de onde sairão os mais preparados trabalhadores, num tempo em que o capital está explorando mais do que a força física, exigindo capacidades intelectuais e de liderança do operariado. Que o digam as lideranças do movimento "Todos pela educação". ${ }^{4}$

Um dos veículos de divulgação utilizado pelo Governo FHC para tornar pública sua política de elaboração do Currículo Básico Nacional foi a Revista Nova Escola..$^{5}$ Em 1995, a Profa. Iara Prado, então Secretária de Educação Fundamental do MEC, concedeu entrevista à revista. Nela esclarece:

1. O currículo era um dos cinco pontos fundamentais da estratégia para o Ensino de Primeiro Grau anunciada pelo Presidente FHC em fevereiro/1995. 
2. Tratava-se de Currículo Básico Nacional, ainda que chamados de Parâmetros Curriculares, pois "a existência de parâmetros curriculares facilita a avaliação do ensino, a formação de professores em âmbito nacional e a produção de livros didáticos. É uma política de curto, médio e longo prazos, que se desenvolverá pelos quatro anos de governo, permitindo atingir nosso principal objetivo que é a qualidade do ensino" (p. 52; grifos nossos).

Perguntada se a existência de currículos mínimos estaduais impedia uma avaliação mais eficaz do ensino, revela ainda a Profa. lara Prado:

Um dos grandes problemas que o Sistema Nacional de Avaliação da Educação Básica (SAEB), organismo do MEC, tem enfrentado é justamente a inexistência de um parâmetro curricular nacional. Nestes últimos dez anos, vinte unidades da Federação, o Distrito Federal inclusive, vêm adotando suas próprias propostas curriculares, o que ocorre também com alguns municípios como São Paulo e Rio de Janeiro. São currículos regionais. Quando o SAEB define o conteúdo com que vai trabalhar para avaliar o ensino, ele esbarra na questão de que alguns Estados não o adotam ou então não aplicam determinado conteúdo da forma que o SAEB quer analisar. Nós agora vamos dar um parâmetro para os Estados. (p. 52-53; grifos nossos)

A entrevistada esclarece também que não chama esses "Parâmetros" de "Currículo Mínimo Nacional", porque pretende ir além de "conteúdos mínimos":

A proposta conterá um currículo básico nas disciplinas Português, Matemática, Ciências e Estudos Sociais. Contudo nossa preocupação é que os parâmetros não sejam apenas um elenco de conteúdos, mas também um apoio para o professor em sala de aula. Por esse motivo não estamos chamando a futura proposta de Currículo mínimo. Nós pretendemos ir além disso. Queremos que os parâmetros sejam uma referência para o professor em sala de aula. (p. 53)

Pode-se situar, então, os PCNs como parte necessária da política de avaliações do sistema, em busca da eficiência e qualidade. Parâmetros e avaliação caminham juntos para construir outra domesticação: aquela dos professores. Estes deverão adaptar todo seu ensino aos parâmetros para que, nas provas nacionais, seus alunos consigam obter resultados positivos (que interferem hoje, como vimos, até para obter bolsas de estudos ou maior facilidade de classificação nos concursos de ingresso para as universidades públicas, não faltando propostas e até mesmo programas de remuneração diferenciada dos professores em função destes mesmos resultados). 
No entanto, o MEC desde sempre sabia que a simples existência de parâmetros e de avaliações não seria suficiente. Outros programas eram necessários para que o corpo de professores pudesse dar conta do previsto nas propostas que os $\mathrm{PCNs}$ consubstanciam. A questão da qualidade da escola pública dependia e depende crucialmente em primeiro lugar das condições sociais de acesso aos bens culturais, de que está distante a população brasileira e os próprios professores; em segundo lugar da qualidade de seus professores, cuja formação, ainda que universitária, é sofrível; ${ }^{6} \mathrm{em}$ terceiro lugar das condições materiais das escolas: estrutura física, recursos didáticos, laboratórios, bibliotecas, acesso à informática etc.

Obviamente, a questão da qualidade da escola pública (não para todos, mas para um novo e seleto quadro de profissionais) não se restringe à situação brasileira, mas correlaciona-se com a nova ordem internacional, que alterou o padrão de exigências até pouco tempo requerido pelo capital. Neste novo contexto, a educação tem um papel estratégico no projeto neoliberal. (SILVA, 1994, p. 14-15)

Para resolver o impasse diante das novas exigências, consubstanciadas nos parâmetros curriculares, a "produtividade" seria auferida pelos resultados escolares, voltando-se para o impacto da educação na sociedade. Estes resultados podem ser definidos como o "atingimento dos objetivos pedagógicos estabelecidos pelo sistema e/ou pela escola. O foco aqui é o desempenho do aluno, o conhecimento que foi transmitido e retido (e não os insumos e/ou os processos)"7 (BRASIL, 1994, p. 37).

Era necessário, portanto, ancorar o professor. E isto foi feito através de dois grandes programas: "Parâmetros em Ação", um conjunto de atividades de formação continuada de professores e, mais eficaz, o Programa Nacional de Livro Didático (PNLD), com a compra dos livros didáticos selecionados por comissão de professores universitários indicados pelo MEC e oferecidos para a escolha das escolas e professores.

Como a formação continuada não tinha continuidade - como sempre, a formação continuada é descontínua - a ancoragem no livro didático achatou praticamente toda a autonomia do professor. Este ficou encurralado: pela frente, a avaliação de desempenho do aluno (o conhecimento retido por ele e supostamente transmitido pela escola); por um lado os livros didáticos gratuitamente distribuídos - qualquer pedido de outro material ou a recusa em usar o que o governo dá sempre traz consequências para o professor; de outro lado os parâmetros curriculares a indicarem o que deve ser ensinado e mesmo como deve ser ensinado (e os livros didáticos estariam dentro destes padrões, segundo as avaliações prévias realizadas pelos especialistas) e mais 
recente, por trás, como água batendo e fazendo nadar no ritmo desejado, as avaliações dos professores e a vinculação de sua remuneração (através de prêmios, salários extraordinários, enfim, certas "gorjetas" que desmobilizam a categoria como um todo) aos resultados obtidos pelos seus alunos nas provas nacionais.

Algumas redes estaduais e municipais estão indo além: a compra de "pacotes" produzidos longe da realidade de seus alunos, onde tudo o que se fará está pré-definido em apostilas, cadernos, livro de orientação do professor etc. O modelo das escolas de sistema apostilado, estilo Anglo, Positivo e outros, modelo mais bem sucedido de lucros neste nicho de mercado em que deve se tornar a escola, é agora transportado para as redes públicas. Mas se os resultados não forem satisfatórios, a culpa sempre será do professor que não soube aplicar o material.

E isto tudo não se fez nem se faz na surdina. Alardeia-se pelo meio de comunicação mais acessível à população: a TV. Tratou-se e trata-se de tornar visível a escola, em seus problemas e em seus sucessos. Daí a importância atribuída à necessidade de sensibilizar o público para o problema educacional. É ilustrativo registrar o tipo de propaganda governamental veiculada na mídia desde 1995, cujos slogans podemos ainda lembrar: "Acorda Brasil, tá na hora da escola!", com empresários falando da importância da escola; a propaganda do governo: "Um grande país começa na sala de aula", enfatizando o tempo pedagógico dentro da sala de aula; "Educação, prioridade nacional, tarefa de todos" e não tarefa do Estado; “Educação. Só assim resolveremos o problema do Brasil"; a campanha "Colabore! Seja amigo da escola", conclamando empresas e público em geral para realizar trabalhos voluntários na escola pública; “Conheça o IDEB da escola de seu filho”, entre outras muitas campanhas institucionais.

Um plano detalhado em execução. Nada melhor do que isso tudo para a domesticação dos agentes educativos.

\section{LUZES NO FIM DO TÚNEL}

Podemos, neste momento, registrar dois grandes motivos para alguma esperança. Comecemos por algumas das razões que levaram à emergência do primeiro motivo, registrando dois fatos:

1. OEstado de S. Paulo (edição de 17/10/2011) publicou matéria sobre os bancos brasileiros: enquanto os trabalhadores contribuíram com 9,9\% da arrecadação federal com o recolhimento do Imposto de Renda, os bancos representaram $4,1 \%$ com o pagamento de seus quatro tipos de tributos. $E$ mais: enquanto qualquer trabalhador tem um desconto de $27,5 \%$ sobre sua 
renda (renda do trabalho), os sócios e acionistas dos bancos recebem juros sobre a participação no capital da instituição, e sobre estes juros (que não são rendas...), o imposto é de apenas $15 \%$.

2. O bilionário Warren Buffett, em artigo recente no New York Times, pediu que os governos deixassem de paparicar os ricos. E"meio envergonhado, o bilionário Buffett explicou que os impostos que pagou somaram 17,4\% de seus vencimentos. Já para 20 funcionários de seu escritório, o valor oscilou entre $33 \%$ e $41 \%$. Lembrou ainda que a taxação dos ricos era bem maior em 1980-90, quando os EUA criaram milhões de empregos".

E a primeira luz no fim do túnel aparece: é a movimentação popular dos indignados que começam a tomar as ruas dos grandes centros. Nunca se defendeu tanto um "estado mínimo" e nunca o estado foi tão profundamente usado pelo capital financeiro: enquanto seus negócios, mesmo que meio escusos, estão dando lucros, nada cabe ao estado; quando há prejuízos antevistos, eis que o cofre público - alimentado pela contribuição do povo - se torna necessário para a "manutenção do sistema financeiro", evitando crises que são produzidas precisamente por este mesmo sistema financeiro, cuja ganância de lucros, mesmo que extraídos dos cofres públicos, é sem limites. Todas as fabulosas somas investidas para evitar crises desaparecem sob as asas destas aves de rapina, e eles mesmos anunciam uma nova crise, para que mais recursos Ihes sejam canalizados. Uma gangorra sem fim.

A retomada do exercício da cidadania, a revolta com um mundo que parecia ter um único caminho, a consciência de que "um outro mundo é possível; uma outra Educação é possível" reacendem os movimentos sociais, também de forma globalizada. E isto constrói esperança.

A segunda luz no fim do túnel tem a ver com mudanças de paradigmas que começam a aparecer na "matriz" do mundo globalizado. Retomemos algumas informações. Publicados os resultados do Enem/2009, o jornal O Estado de S. Paulo organizou, para sua edição de 19/7/2010, um caderno especial, cuja manchete principal é "Quanto valem as melhores escolas?". São oito páginas comentando resultados do Exame Nacional, listando as 100 escolas destacadas, mas dedicando seus textos somente para as 10 primeiras. Uma conclusão mais ou menos óbvia: a escola com melhor nota é também a mais cara. A melhor é também escola de tempo integral: são 12 horas na escola. Claro, pais reclamando do excesso de exigências para crianças de 11 ou 12 anos.

Enfim, aconselhando os pais na escolha da melhor escola, ${ }^{9} \mathrm{o}$ jornal cumpre sua tarefa complementar às avaliações nacionais: estas estabelecem a hierarquia (ainda que especialistas e defensores dos exames digam que não 
é este o objetivo do Exame Nacional). Competição, competência, eficiência no ensino, anuidades, ${ }^{10}$ estas são, entre outras, as variáveis a serem consideradas pela "clientela" pagante, mas (pasmem!) há uma escola pública na Lapa que está "roubando" alunos da rede particular. ${ }^{11} \mathrm{E}$ há escolas fazendo propaganda de seus sistemas de seleção de alunos: só aceita os melhores! $E$ eis que as avaliações atingem seu ápice: a construção efetiva de uma meritocracia ao gosto do mercado. A mesa está posta.

Mas, menos de 15 dias depois, ${ }^{12}$ o mesmo jornal publica entrevista com Diane Ravitch, ex-secretária-adjunta de Educação dos EUA no governo George Bush, mas desde o governo Bill Clinton diretora do National Assessment Governing Board, instituto responsável pelos testes federais daquele país. E eis a novidade:

Eu apoiei as avaliações, o sistema de accountability (responsabilização de professores e gestores pelo desempenho dos estudantes) e o programa de escolha por muitos anos, mas as evidências acumuladas nesse período sobre os efeitos de todas essas políticas me fizeram repensar. Não podia mais continuar apoiando essas abordagens. O ensino não melhorou e identificamos apenas muitas fraudes no processo.

E mais adiante, vale a pena conferir:

Avaliações padronizadas dão uma fotografia instantânea do desempenho. Elas são úteis como informação, mas não devem ser usadas para recompensas e punições, porque, quando as metas são altas, educadores vão encontrar um jeito de aumentar artificialmente as pontuações. Muitos vão passar horas preparando seus alunos para responderem a esses testes, e os alunos não vão aprender os conteúdos exigidos nas disciplinas, eles vão apenas aprender a fazer essas avaliações. Testes devem ser usados com sabedoria, apenas para dar um retrato da educação, para dar uma informação. Qualquer medição fica corrompida quando se envolve [sic] outras coisas num teste.

Por fim, afirma:

A lição mais importante que podemos tirar do que foi feito nos Estados Unidos é que o foco deve ser sempre em melhorar a educação e não simplesmente aumentar as pontuações nas provas de avaliação. Ficou claro para nós que elas não são necessariamente a mesma coisa. Precisamos de jovens que estudaram história, ciência, geografia, matemática, leitura, mas o que estamos formando é uma geração que aprendeu a responder testes de múltipla escolha. Para ter uma boa educação, precisamos saber o que é uma boa educação. E é muito mais que saber fazer uma prova. Precisamos nos preocupar com as necessidades dos estudantes, para que eles aproveitem a educação. 
É incrível que, na mesma página, nosso Ministro de Educação afirma: "O Enem vai ajudar a organizar um currículo mais racional. Esse rolo compressor que é a assimilação mecânica de matéria tem de mudar". E o que é mais mecânico do que aprender a responder aos testes?

Considerando ainda que não há educação possível sem passar pela linguagem - ela perpassa toda a vida social e nós humanos somos sujeitos falantes e não objetos inertes - esse rolo compressor acabou por fazer desaparecerem todas as iniciativas de ensino diferenciadas em função das avaliações. A área do ensino de linguagem certamente foi uma das mais atingidas, porque nela desde a década de 1980 havia trabalhos escolares diferenciados, sem seguir sempre a mesma rotina e sem definir objetos de estudo que pudessem ser "cobrados" em testes. Havia um grande esforço em substituir o ensino de objetos (a descrição da língua, como apresentada pelas gramáticas tradicionais) para um ensino centrado em práticas linguageiras de leitura, escrita e discussão ou análise dos recursos expressivos mobilizados nos textos sob leitura ou produzidos pelos próprios alunos..$^{13} \mathrm{Um}$ deslocamento se fez aí necessário: este deslocamento foi a definição de um objeto de ensino (objetivo, cobrável pelas provas) para substituir as práticas que vinham acontecendo. Este objeto construído foram os gêneros do discurso, com referência necessária a Bakhtin em que as propostas das práticas se baseavam, mas levando em conta seu princípio fundamental do enunciado concreto e da interação verbal como realidade efetiva da língua. A primeira alteração a fazer no que diz Bakhtin é esquecer sua afirmação de que os gêneros são "relativamente estáveis" e que estão vinculados diretamente às esferas da comunicação humana. Esquece-se o "relativamente", descrevem-se os gêneros e as situações (esferas) de uso, e passa-se a ensinar este objeto (em outros termos, esta descrição!). E agora há um objeto palpável sobre que organizar provas de retenção de conhecimentos.

Como sabemos, responder a testes - isso agora é reconhecido oficialmente pela matriz ideológica dos testes - não ajuda a ler e a escrever. Na nossa própria história da educação encontramos uma reação a isso como resposta ao tecnicismo educacional da década de 1970: em meados desta década, assustados com a pouca habilidade dos universitários em ler e escrever, reintroduziu-se nos vestibulares a prova de redação. Felizmente, os ventos parecem estar mudando.

A voz da educadora Diane Ravitch é secundada mais recentemente pelo economista David Figlio, ${ }^{14}$ que em sua entrevista recomenda "que as escolas sejam avaliadas com base na evolução do aluno e não apenas nos níveis de proficiência, que cada colégio tenha um objetivo que seja desafiador 
e, ao mesmo tempo, possível". Vem por aí, na voz de um economista, outras indicações: uma avaliação de processo e com base em diferentes objetivos o que significa aceitar novamente a diversidade em lugar de parâmetros nacionais independentes das condições reais das escolas ou das redes de ensino.

É bom termos uma reviravolta na matriz! Talvez a responsabilização dos professores e gestores comece a arrefecer-se. Pode ser que a obra The Death and Life of the Great American School System (A morte e a vida do grande sistema escolar americano) de Diane Ravitch nos ajude, que a voz do economista David Figlio seja ouvida pelos que ditam nossas políticas educacionais, já que estamos acostumados a ouvidos moucos à crítica local aos sistemas de avaliação, à crítica à hierarquização das escolas, à crítica à violência de colocar em teste crianças de oito anos, à crítica à responsabilização do professor e à criação de abonos ou salários diferenciados em função dos sucessos nos exames.

Quando a matriz está em crise, começa questionar suas certezas, tudo pode começar a mudar de rumo. Ouviremos logo mais vozes críticas, entre elas muitas daquelas que se comprometeram com os sistemas de avaliação e seus parâmetros. Elas serão bem vindas no coro polifônico com que as mudanças para uma outra educação possível será construída sem rigidez e com muita flexibilidade.

\section{THE DOMESTICATION OF EDUCATIONAL AGENTS. IS THERE LIGHT AT THE END OF THE TUNNEL}

ABSTRACT: This study takes up the question of the triadic relationship underlying the educational profession: students, teachers and knowledge, showing how this has defined different "identities" for the teacher throughout history. In recent decades especially, national curriculum policies, national assessments and the program for acquiring textbooks or even educational packages have resulted in the domestication of educational agents who let their teaching be guided by the demands imposed by the system as a whole, leading to an almost total loss of their autonomy. The light at the end of the tunnel comes precisely from the political spaces which inspired this same domestication: the North-American model which, having failed, decides to build a greater autonomy in educational and pedagogical processes. This process is exemplified using the teaching of language as a basis.

KEYwORDS: Teacher formation. Professional identity. Language teaching. Assessment. 


\section{NOTAS}

1. A primeira grande expansão e interiorização do ensino superior privado se deram nos anos 1960/1970 como prêmio da ditadura à classe média pelo apoio político. Ao mesmo tempo em que se empobrecia, a classe média via seus filhos portarem diplomas de cursos superiores, pelos quais pagou, obtidos em faculdades, a maioria faculdades isoladas e sem condições efetivas de funcionamento.

2. Aliás, aconteceu e acontece frequentemente nas avaliações dos cursos de pósgraduação, realizadas pela Capes e baseadas unicamente em critérios numéricos. Para fugir aos critérios numéricos, criou-se um sistema de avaliação das revistas científicas: as notas maiores são para publicações mais bem colocadas nesta nova hierarquização realizada sem qualquer respeito pelos objetivos e públicos a serem atingidos pelos artigos produzidos.

3. Um dos autores deste artigo participou de uma reunião, numa grande e conceituada universidade, em que um professor chegou a propor que todos os cursos tivessem uma disciplina para preparar para a prova e cuja avaliação final seria a nota obtida na prova nacional, de modo que o estudante que viesse a boicotar o exame, de qualquer forma, jamais concluiria o curso porque não teria aprovação na disciplina.

4. Jorge Gerdau, em entrevista ao Estado de S. Paulo, em resposta à pergunta sobre as razões de seu envolvimento com o movimento "Todos pela Educação" - que não é a mesma coisa que uma educação de qualidade para todos - foi extremamente explícito e didático. Sua fábrica não conseguia a mesma produtividade das fábricas japonesas, apesar da tecnologia e organização do trabalho. Reunidos para avaliar a questão, verificaram que a grande diferença era a escolaridade dos trabalhadores. O Grupo Gerdau, em consequência, organizou programa de escolarização de seus funcionários, de modo que hoje qualquer um dos trabalhadores do grupo deve ter ensino médio. A produtividade se equiparou àquela das fábricas japonesas.

5. Revista Nova Escola. S. Paulo, ano X, n. 83, abr. 1995.

6. Em recente trabalho para o Sindicato dos Profissionais da Educação do Estado de Sergipe, tivemos a oportunidade de encontro com mais de 1.300 professores de cidades do interior daquele estado. Todos eles tinham curso superior, os cursos possíveis dentro de suas realidades. Há que registrar este feito do magistério brasileiro: em uma só geração, filhos de analfabetos ou de baixíssima escolaridade, os professores deram um salto de escolarização, realizando curso de nível superior. Como todo o salto, este também produziu um vácuo cujo preenchimento só poderá acontecer à medida que os professores venham a ter acesso aos bens culturais que sempre foram negados às famílias de que procedem.

7. É importante salientar que retiramos esta passagem de um documento produzido no interior da Secretaria de Planejamento (atual Ministério do Planejamento), e não propriamente de um documento do MEC. Em trabalho anterior (GERALDI, 2000) este documento é analisado em profundidade porque mostra em que área efetivamente 
se definem, e com larga antecedência, as políticas educacionais que vieram a ser implementadas durante todo o governo FHC e em grande parte no governo Lula.

8. A citação é extraída da crônica de Ricardo Melo, Folha de S.Paulo, 18/8/2011.

9. Há até um texto cujo título é “Pais não devem decidir só pelo Enem": nem sempre a escola top é a mais adequada em função dos valores, dos projetos pedagógicos etc., apontam as especialistas consultadas.

10. A nota do Enem é basilar, mas metade dos alunos das escolas de elite não compareceu à prova! As boas notas obtidas por aqueles que compareceram realmente mostram algum perfil da escola? Não poderiam ser também escolhidos para comparecer? 11. Ou seja, quando uma escola pública entra na competição e se aproxima dos topos, é privatizada por dentro pela clientela, clientela desejada para que os escores dos próximos anos sejam cada vez melhores.

12. Iwasso, Simone. Nota mais alta não é educação melhor. Entrevista. O Estado de S. Paulo, edição de 2/8/2010 (Primeiro Caderno, p. 16).

13. Cf. Geraldi, J. W. (2010b).

14. Ocimara Balmant. "Cada escola deve ter uma meta desafiadora, mas possível". Entrevista com David Figlio, apresentado por O Estado de S.Paulo (17/10/2011), como professor de economia, educação e políticas sociais do Instituto para Pesquisas Políticas da Universidade de North Western e como pesquisador associado do National Bureau of Economic Research nos Estados Unidos.

\section{REFERÊNCIAS}

BRASIL/SEPLAN. Educação Fundamental: Relatório Final. Proposta de estudos sobre alternativas para o desenvolvimento do semi-árido com ênfase na municipalização. Grupo de Trabalho de Recursos Humanos. Recife, setembro, 1994.

FREIRE, Paulo. Pedagogia da autonomia. Saberes necessários à prática educativa. 7. ed. Rio de Janeiro: Paz e Terra, 1998.

GERALDI, Corinta Maria Grisolia. A formação inicial e continuada do professor das séries iniciais. In: MEC/UNESCO. Por uma política de formação de professores para a educação básica. Anais do Seminário Nacional sobre Formação de Professores para a Educação Básica. Brasília: MEC; Belo Horizonte: Fundação AMAE, 1994. p. 67-82.

GERALDI, Corinta Maria Grisolia. Políticas curriculares oficiais e globais: algumas explicações sobre sua implantação no Brasil - o caso dos Parâmetros Curriculares Nacionais do Ensino Fundamental. Texto apresentado no V Colóquio sobre Questões curriculares e I Colóquio Luso-brasileiro. Minho: Universidade do Minho, 2000. p. 195-206. v. I.

GERALDI, João Wanderley. “Erros e acertos para além do ensino”. Texto apresentado no III Congresso Cotidianos Diálogos sobre Diálogos, na Universidade Federal Fluminense, na mesa-redonda "Ambiguidade do erro", em 11/8/2010. 
GERALDI, João Wanderley. Deslocamentos no ensino: de objetos a práticas; de práticas a objetos. In: GERALDI, J. W. A aula como acontecimento. São Carlos: Pedro \& João Editores, 2010b.

SILVA, T. T. A nova direita e as transformações na sociedade e na educação. In: GENTILI, P.; SILVA, T. T. (Orgs.). Neoliberalismo, qualidade total e educação. Petrópolis: Vozes, 1994. p. 9-29.

Corinta MARIA Grisolia Geraldi é professora doutora, aposentada, e colaboradora do Programa de pós-graduação em Educação da Unicamp. Tem experiência na área de Educação, com ênfase em Ensino e Formação de Professores, atuando principalmente nos seguintes temas: ensino-pesquisa, trabalho docente, currículo em ação, cotidiano escolar. E-mail: corintageraldi@yahoo.com.br

JoÃo WANDERLEY GeraldI é professor titular aposentado do Instituto de Estudos da Linguagem da Unicamp. Foi professor visitante da Universidade do Porto e da Universidade de Aveiro (Portugal), e de universidades brasileiras. Atua principalmente nos seguintes temas: análise do discurso, estudos bakhtinianos e ensino de língua portuguesa.

E-mail: jwgeraldi@yahoo.com.br 